\title{
A hospital cost analysis of a fibrin sealant patch in soft tissue and hepatic surgical bleeding
}

This article was published in the following Dove Press journal:

ClinicoEconomics and Outcomes Research

21 September 2016

Number of times this article has been viewed

\author{
Mitra Corral' \\ Nicole Ferko ${ }^{2}$ \\ Andrew Hogan ${ }^{2}$ \\ Sarah S Hollmann² \\ Gaurav Gangoli' \\ Nadine Jamous ${ }^{3}$ \\ Jonathan Batiller' \\ Richard Kocharian'
}

'Ethicon BioSurgery, Somerville, NJ, USA; ${ }^{2}$ Cornerstone Research Group, Burlington, ON, Canada; ${ }^{3}$ Ethicon

Biosurgery, Wokingham, Berkshire, UK
Correspondence: Nicole Ferko

Cornerstone Research Group, 204-3228

South Service Road, Burlington Ontario,

L7N 3H8, Canada

Tel + I 905637623 I ext 236

Emailnferko@cornerstone-research.com
Background: Despite hemostat use, uncontrolled surgical bleeding is prevalent. Drawbacks of current hemostats include limitations with efficacy on first attempt and suboptimal ease-ofuse. Evarrest ${ }^{\circledR}$ is a novel fibrin sealant patch that has demonstrated high hemostatic efficacy compared with standard of care across bleeding severities. The objective of this study was to conduct a hospital cost analysis of the fibrin sealant patch versus standard of care in soft tissue and hepatic surgical bleeding.

Methods: The analysis quantified the 30-day costs of each comparator from a hospital perspective. Published US unit costs were applied to resource use (ie, initial treatment, retreatment, operating time, hospitalization, transfusion, and ventilator) reported in four trials. A "surgical" analysis included resources clinically related to the hemostatic benefit of the fibrin sealant patch, whereas a "hospital" analysis included all resources reported in the trials. An exploratory subgroup analysis focused solely on coagulopathic patients defined by abnormal blood test results. Results: The surgical analysis predicted cost savings of \$54 per patient with the fibrin sealant patch compared with standard of care (net cost impact: $-\$ 54$ per patient; sensitivity range: $-\$ 1,320$ to $\$ 1,213)$. The hospital analysis predicted further cost savings with the fibrin sealant patch (net cost impact of $-\$ 2,846$ per patient; sensitivity range: $-\$ 1,483$ to $-\$ 5,575$ ). Subgroup analyses suggest that the fibrin sealant patch may provide dramatic cost savings in the coagulopathic subgroup of $\$ 3,233$ (surgical) and $\$ 9,287$ (hospital) per patient. Results were most sensitive to operating time and product units.

Conclusion: In soft tissue and hepatic problematic surgical bleeding, the fibrin sealant patch may result in important hospital cost savings.

Keywords: cost, soft tissue bleeding, hepatic bleeding, surgical bleeding, coagulopathic, fibrin sealant patch, hospital, health economics

\section{Introduction}

Surgical bleeding is a common occurrence and varies widely in presentation and consequences across surgery types. ${ }^{1-5}$ Surgical bleeding can range from mild or moderate in intensity to uncontrolled or traumatic. Some bleeding scenarios may be straightforward to manage; however, bleeding can also become more problematic, depending on several factors, including bleeding intensity, anatomic location, visibility and accessibility of bleeding source, and coagulation status. ${ }^{6}$ Problematic types of bleeding scenarios may be referred to in the literature using several common bleeding terms, including severe, major, uncontrollable, or excessive. For example, diffuse bleeding from broad surface areas in coagulopathic patients may be difficult 
to control, which can lead to complications, such as transfusions. ${ }^{1,6,7}$ Uncontrollable bleeding is also often encountered in fragile or friable tissues, such as in liver resections. ${ }^{1,4,5}$

Problematic surgical bleeding is frequently associated with important clinical and cost burden. ${ }^{8-12}$ Literature capturing "excessive" or "uncontrolled" surgical bleeding reported mortality rates as high as $20 \%$, with a fivefold increase in death if coagulopathy is present. ${ }^{2,7}$ Problematic bleeding can also be associated with substantial hospital resource use due to increased risk of transfusion, higher risk of complications, longer procedure times, and reoperation..$^{2,4,9,13-16}$ A large, US premier database study demonstrated that all-cause costs were significantly higher in patients with uncontrolled $(\$ 24,203$ to $\$ 61,323)$ compared with controlled $(\$ 14,420$ to $\$ 45,593)$ bleeding $(P<0.001) .{ }^{17}$

In some bleeding situations, conventional surgical methods (eg, sutures or clips) to control bleeding may be impractical or ineffective. ${ }^{16,18,19}$ As a result, these situations often require the use of adjunctive agents, such as topical absorbable hemostats or fibrin sealants. ${ }^{1,20}$ Although there are several products available, their efficacy in controlling bleeding can be limited, with uncontrolled bleeding remaining a prevalent problem. ${ }^{17,21}$ Recent data have highlighted this issue by demonstrating that $32 \%$ to $68 \%$ of surgical cases involve major bleeding, despite the use of current hemostatic agents. ${ }^{17}$

The Evarrest ${ }^{\circledR}$ Fibrin Sealant Patch (Ethicon U.S., LLC, Somerville, NJ, USA) is an advanced topical absorbable hemostat composed of well characterized and commonly used materials (polyglactin [PG910], oxidized regenerated cellulose [ORC], human thrombin, and human fibrinogen). There is a growing body of evidence that demonstrates the safety and effectiveness of this fibrin sealant patch in a variety of tissue types and across a spectrum of bleeding intensities..$^{22-25}$ In mild-to-moderate soft tissue surgical bleeding, 98.3\% of patients with the fibrin sealant patch and $53.3 \%$ with Surgicel ${ }^{\circledR}$ Original (Ethicon U.S., LLC, Somerville, NJ, USA) achieved hemostasis at 4 minutes $(P<0.0001){ }^{22}$ This treatment differential was magnified with increasing bleeding intensity. Another trial in severe soft tissue bleeding showed that the fibrin sealant patch was also safe and effective compared with standard of care (SoC) (ie, gauze \pm ORC). ${ }^{23}$ In the two hepatic tissue surgical bleeding trials, $82.5 \%$ and $95.7 \%$ of patients with the fibrin sealant patch compared to $29.5 \%$ and $42.9 \%$ of patients with SoC achieved hemostasis at 4 minutes $(P<0.001))^{24,25}$ In these hepatic bleeding trials, SoC was sometimes an ORC and sometimes manual compression with or without another type of hemostat. Several types of resource (eg, transfusions, retreatment) have been reported to be numerically lower with the fibrin sealant patch in the trials. ${ }^{22-25}$
In light of recent health care reform measures, it is essential for hospitals to optimize resource use in hospitals. The clinical trial data for the fibrin sealant patch in soft tissue and hepatic surgical bleeding capture important hospital resource outcomes. The objective of our study was to therefore perform a modeled hospital cost analysis for the fibrin sealant patch compared with SoC across a range of hepatic and soft tissue bleeding scenarios.

\section{Methods}

A cost analysis model, developed using Microsoft Excel 2007 (Microsoft Corporation, Redmond, WA, USA), quantified the 30-day per patient cost impact of the fibrin sealant patch compared with SoC from a hospital decision-maker perspective (eg, value analysis committees). The analysis incorporated aggregated resource use from four clinical trials of the fibrin sealant patch versus SoC in surgical bleeding, in which the SoC arm varied to some extent across trials. ${ }^{22-25}$ The soft tissue surgical bleeding trials primarily compared the fibrin sealant patch with ORC/Surgicel ${ }^{\circledR}$ Original $\left(88 \%{ }^{23}\right.$ to $100 \%{ }^{22}$ ORC/Surgicel ${ }^{\circledR}$ Original). The two hepatic surgical bleeding trials compared the fibrin sealant patch with a mix of ORC (ie, 34\% to 69\%) and conventional methods (or other hemostats). ${ }^{24,25}$ Table S1 provides the detailed breakdown of products used as the initial treatment in the SoC arm of the four clinical trials. The primary outcome in all trials was the proportion of patients achieving hemostasis at 4 minutes. Further, the definitions for resource data collection remained generally consistent across all four trials. Published US unit costs were assigned to resource outcomes, and the total costs of the fibrin sealant patch and $\mathrm{SoC}$ were quantified. The study population therefore reflects a broad range of patients across several surgical specialties (excluding transplant patients). Ethics approval was gathered for the clinical studies that informed this costing analysis. As the costing analysis in this study did not involve contacting patients or obtaining further data than what was already reported in the clinical study, ethics approval was not obtained for the current costing analysis.

\section{Resource inputs from clinical trial}

In the budget impact analysis, resource outcomes were based on data reported for the intention-to-treat populations and incorporated using mean values across treatment groups where applicable. The resource outcomes were collected from multinational trials, including the US, Europe, Australia, and New Zealand. ${ }^{22-25}$ For initial product cost, the actual amount and size of the fibrin sealant patch were quantified. Using individual patient level data, target bleeding site $<52 \mathrm{~cm}^{2}$ were 
treated with a single fibrin sealant patch while those target bleeding sites $>52 \mathrm{~cm}^{2}$ received two units. For each trial, the average initial units of the fibrin sealant patch ranged from 1.02 to 1.48 per patient. In the mild-to-moderate soft tissue bleeding trial, all SoC patients received a single unit of Surgice ${ }^{\circledR}$ Original. ${ }^{22}$ In the severe soft tissue bleeding trial, 28 of the SoC patients received ORC and four received alternative products (ie, collagen, thrombin, manual compression, suture, ligation, and cautery).$^{23}$ In hepatic bleeding trials, all SoC patients received manual compression with or without additional conventional methods or hemostatic products (eg, ORC, gelatin, TachoComb/TachoSil ${ }^{\circledR}$ [Baxter Healthcare Corporation, Westlake Village, CA, USA], suture, argon beam, diathermy, and Surgicel ${ }^{\circledR}$ Fibrillar [Ethicon U.S., LLC, Somerville, NJ, USA]). ${ }^{24,25}$ Details of the SoC breakdown taken from the clinical study reports (ie, available to the public via correspondence with authors) can be found in Table S1.

Mean trial-reported values were used in the budget impact analysis for operation time, transfusion risk prior to discharge, transfusion units, retreatment risk and related product use, length of postoperative stay, and ventilator hours. These outcomes were incorporated into the analysis regardless of statistical significance. For transfusion units, all products were included in the analysis (ie, packed red blood cells, whole blood, fresh frozen plasma, platelets, cryoprecipitate, albumin, autologous blood, and leuko-depleted blood). In the trials, if hemostasis was not achieved after 4 minutes, retreatment was defined as the need for additional intervention due to bleeding at the target bleeding site during an additional 6-minute observation period. Retreatment product utilization was quantified per patient based on actual product usage reported from the clinical trials (Table S2). The majority of outcomes had minimal amounts of missing data (ie, <5\%) and therefore imputations were generally not conducted. Data were imputed in one case where the transfusion units were not recorded for two fibrin sealant patch patients and one SoC patient. In these cases, imputation was completed based on respective patient-reported blood loss.

\section{Cost inputs}

Aggregated resource outcomes reported in the trials were costed using published sources and inflated to 2015 US costs using the Consumer Price Index for US medical care. ${ }^{26}$ Unit costs for all products used in the four trials are outlined in Tables S1 and S2. The initial hemostat application cost was based on the specific product size (if noted). List or published prices were applied. If product size was not noted in the clinical study report, the average unit cost across product sizes was applied. For the fibrin sealant patch, each $5.1 \times 10.2 \mathrm{~cm}$ pad was assigned a unit cost of $\$ 1,300 .{ }^{27}$ For SoC, acquisition cost was calculated for each trial based on use and unit costs. In cases where nonconsumable conventional methods were used, it was conservatively assumed that no cost be attributed as these options would have been available as part of routine hemostatic methods. With manual compression, an average of several unit prices was used for BloodSTOP hemostatic gauze to reflect the need for some gauze during this practice. ${ }^{28}$ Other assumptions used in the analysis include the unit cost of collagen and gelatin, which were assumed to be the prices of TachoSil ${ }^{\circledR}$ and Surgiflo ${ }^{\circledR}$ (Ethicon U.S., LLC, Somerville, NJ, USA), respectively. The overall weighted SoC product acquisition costs are summarized in Table 1.

The cost of operating room time was taken from a study that reported a fee of $\sim \$ 62$ per minute. ${ }^{29}$ This cost was added to per minute reported salary for an operating room nurse $(\$ 0.61)^{30}$ and anesthesiologist fee $(\$ 6.65)^{31}$ to formulate a cost of $\$ 92.54$ per 1 minute of surgery after inflation to 2015 dollars. The cost of hospital stay was informed by the Kaiser Family Foundation, with a cost of \$2,186 per day. ${ }^{32}$ This was multiplied by $59 \%$ to account for room and board only, resulting in a cost of $\$ 1,290$ per day, which was used in the analysis. ${ }^{33}$ Unit costs for various transfusion blood products were taken from published literature. ${ }^{34-36}$ For each trial, a weighted average cost for each blood unit type was calculated for the treatment groups with 2015 average cost per unit ranging from $\$ 223$ to $\$ 255$. These values reflected blood acquisition costs only and did not include indirect costs. The hourly cost of ventilator use was reported as the daily cost of mechanical ventilation in intensive care and inflated to $\$ 96.66$ per hour. ${ }^{37}$

Table S2 captures unit costs and weighted average costs for retreatment according to treatment arms for the four clinical studies. No additional costs were conservatively assumed for nonconsumable conventional methods. The weighted average cost of retreatment for the overall trial population was calculated to range from $\$ 90.06$ to $\$ 347.90$ per patient across the four trials.

\section{Base case analysis}

Table 1 summarizes the resource use and unit cost input values used in the base case cost analysis. The surgical analysis included resources deemed more clinically related to the significant hemostatic benefit of the fibrin sealant patch compared with SoC. These resources included the initial application products, retreatment products, surgery time, and transfusion use. A hospital analysis was also conducted 


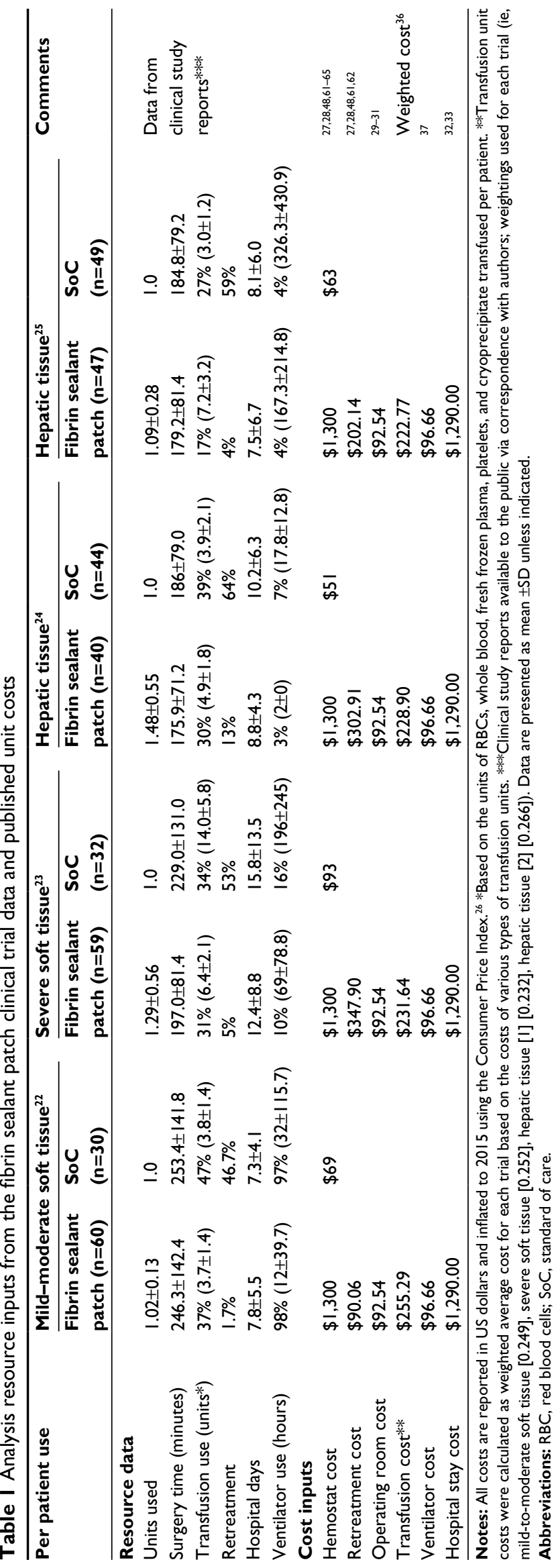

that included all key resource outcomes reported in the trials. Both surgical and hospital analyses were conducted by calculating total costs for each trial (ie, resource use multiplied by unit costs) and weighting the results of the four trials by the trial sample sizes to estimate the composite total costs across trials. The weighting factors can be found in Table 1 (footnote).

\section{Subgroup analysis (coagulopathic patients)}

Exploratory subgroup analyses of both the surgical and hospital analyses were conducted to assess the economic impact in coagulopathic patients. Patients were determined to be potentially coagulopathic and included in the analyses if any coagulation test parameter was outside of the reference range reported by the National Library of Medicine. Inclusion ranges were: $>13.5$ seconds prothrombin time, $>35$ seconds activated partial thromboplastin time, $>1.1$ international normalized ratio, and $<2 \mathrm{~g} / \mathrm{L}$ fibrinogen. ${ }^{38-40}$

Aggregated clinical resource and cost inputs specific for these subgroup analyses are described in Table 2 . The average initial fibrin sealant patch utilization was conservatively assumed to be the same as the base case analysis. Similar to the base case, results were calculated based on weighted average resource use reported from the four clinical trials.

\section{Sensitivity analysis}

Uncertainty around analysis inputs was evaluated in a series of sensitivity analyses for both the surgical and hospital analyses using the overall four-trial composite results as the base case. One-way sensitivity analyses, varying individual fibrin sealant patch and SoC inputs concurrently, were conducted on all cost and resource inputs. These inputs were varied by standard deviation if available, or by adjusting base case values by $\pm 20 \%$. In addition to these sensitivity analyses, alternative inputs were tested according to the following:

- Initial fibrin sealant patch units: For lower and upper range estimates, it was assumed that all patients receive one pad $(\$ 1,300)$ or all patients receive two pads $(\$ 2,600)$.

- Procedure time: Instead of surgery time, total operation time reported in the trials was used (ie, fibrin sealant patch: 317 minutes, SoC: 316 minutes, ${ }^{22}$ fibrin sealant patch: 266 minutes, SoC: 295 minutes $;{ }^{23}$ fibrin sealant patch: 245 minutes, SoC: 258 minutes ${ }^{24}$ and fibrin sealant patch: 273 minutes, SoC: 283 minutes $^{25}$ ).

- Transfusion risk: As an alternative to transfusions to discharge, transfusions until study end were analyzed 


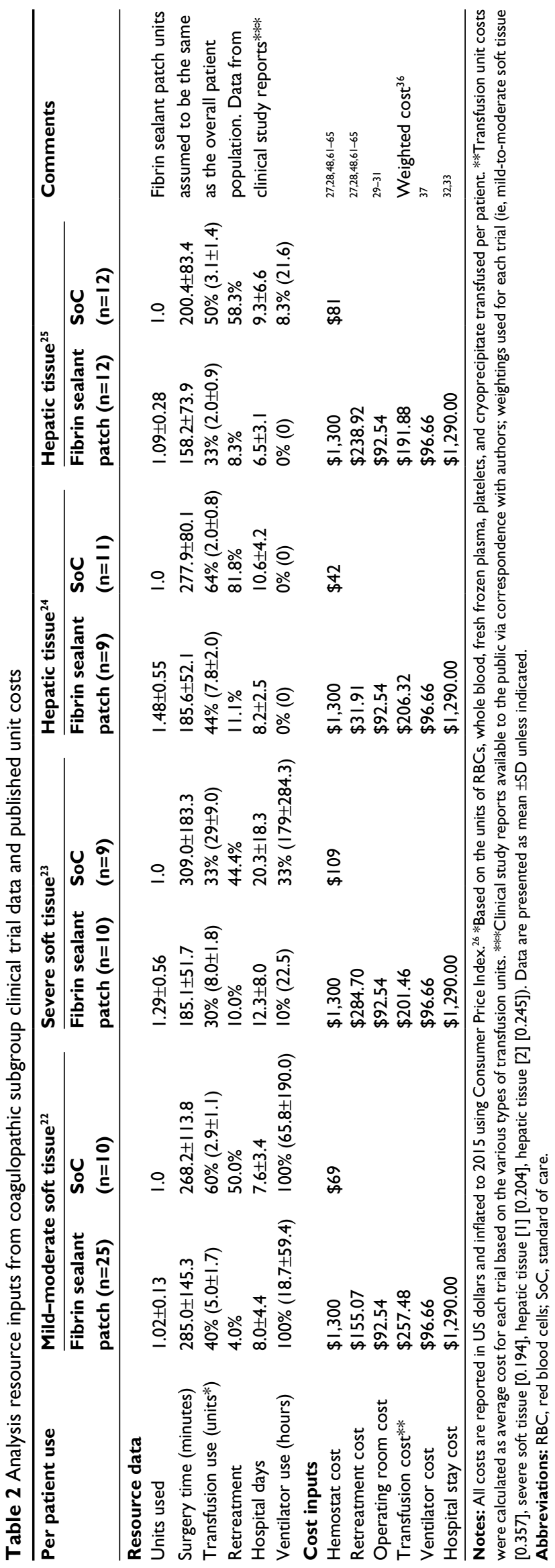

(ie, fibrin sealant patch: 37\%, SoC: 53\%, ${ }^{22}$ fibrin sealant patch: $34 \%$, SoC: $34 \% ;{ }^{23}$ fibrin sealant patch: $30 \%$, SoC: $41 \% ;{ }^{24}$ and fibrin sealant patch: $19 \%$, SoC: $29 \%{ }^{25}$ ).

- Transfusion unit costs: Instead of all blood unit types, only the costs of packed red blood cell units (ie, \$264 per unit) were incorporated. ${ }^{36} \mathrm{An}$ alternative total transfusion unit cost of $\$ 522$ was also used as it included direct and indirect costs associated with a transfusion. ${ }^{5}$

- Hospital length of stay: Instead of postoperative stay, total length of stay was assessed (ie, fibrin sealant patch: 8.9 days, SoC: 8.0 days, ${ }^{22}$ fibrin sealant patch: 14.4 days; SoC: 19.9 days ${ }^{23}$ fibrin sealant patch: 9.4 days, SoC: 10.9 days; ${ }^{24}$ and fibrin sealant patch: 7.8 days, SoC: 8.4 days $\left.^{25}\right)$.

- Transfusion complications: The risk of transfusion complications and associated unit costs were included based on literature estimates. ${ }^{41-43}$

- Operation costs: The costs for operation time were varied according to alternative rates from published literature (ie, upper: $\$ 133$ per minute; lower: $\$ 22$ per minute). ${ }^{44}$

\section{Results}

The cost analysis predicted that the fibrin sealant patch compared with SoC is a cost-saving strategy for hospitals when used in soft tissue and hepatic surgical bleeding (Figure 1A and B; Table 3). The fibrin sealant patch was predicted to result in cost savings of $\$ 54$ and $\$ 2,846$ per patient, for the surgical and hospital analyses, respectively. Costed resource utilization was lower with the fibrin sealant patch compared with $\mathrm{SoC}$ for the majority of resources collected across all four trials (Table 3).

When considering only the soft tissue bleeding trials, the surgical analysis estimated that resource savings with the fibrin sealant patch completely offset its acquisition cost and resulted in a cost savings of $\$ 909$ per patient compared with SoC. For the two hepatic bleeding trials, the surgical analysis estimated that the fibrin sealant patch was associated with a marginal cost impact of $\$ 788$ per patient compared with SoC. Hospital analyses predicted cost savings for both the soft tissue trials $(\$ 4,837$ per patient) and the hepatic bleeding trials ( $\$ 863$ per patient) (data not shown).

For the potentially coagulopathic subpopulations of the four trials, this exploratory analysis estimated that the use of the fibrin sealant patch compared with SoC would result in even greater cost savings for hospitals (Table 3 ). In the surgical analysis, the net difference in resource use was $\$ 4,693$, which completely offset the incremental product acquisition cost $(\$ 1,459)$, resulting in a total cost savings of $\$ 3,233$ per patient 

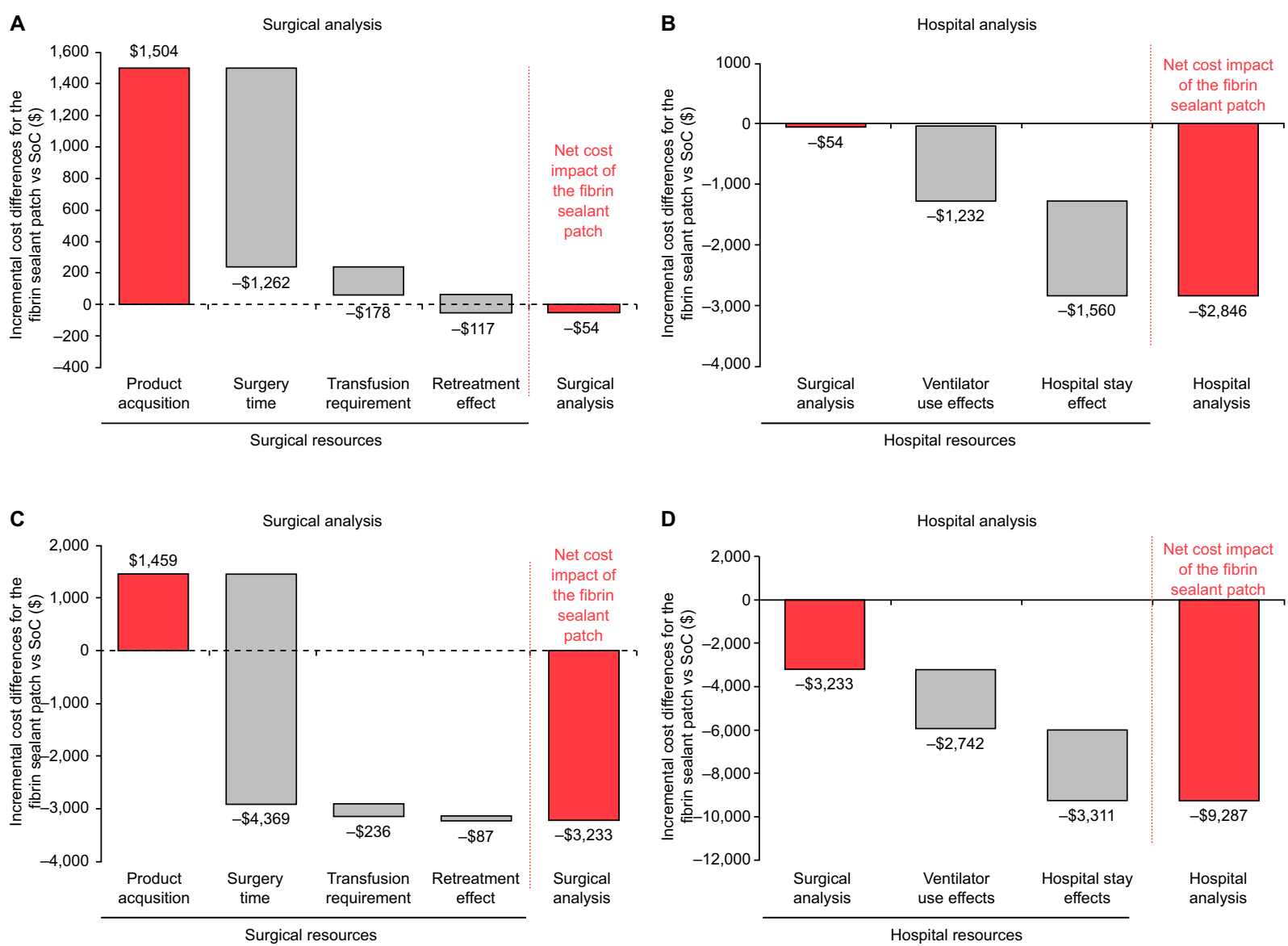

Figure I Resource savings and net cost impact of the fibrin sealant patch compared with SoC.

Note: Results are shown for combined soft tissue and hepatic bleeding for (A) overall population (surgical analysis), (B) overall population (hospital analysis), (C) coagulopathic patients (surgical analysis), and (D) coagulopathic patients (hospital analysis).

Abbreviation: SoC, standard of care.

Table 3 Total cost breakdown per patient for the use of the fibrin sealant patch and SoC

\begin{tabular}{|c|c|c|c|c|c|c|}
\hline \multirow[t]{2}{*}{ Resource } & \multicolumn{3}{|c|}{ Overall population - combined four trials } & \multicolumn{3}{|c|}{ Coagulopathic subgroup of four trials } \\
\hline & $\begin{array}{l}\text { Fibrin sealant } \\
\text { patch }\end{array}$ & SoC & Net difference & $\begin{array}{l}\text { Fibrin sealant } \\
\text { patch }\end{array}$ & SoC & $\begin{array}{l}\text { Net } \\
\text { difference }\end{array}$ \\
\hline \multicolumn{7}{|l|}{ Surgical analysis } \\
\hline Surgery time & $\$ 18,479.14$ & $\$ 19,740.96$ & $-\$ 1,261.82$ & $\$ 19,829.41$ & $\$ 24,198.44$ & $-\$ 4,369.03$ \\
\hline Transfusion use & $\$ 340.50$ & $\$ 518.92$ & $-\$ 178.42$ & $\$ 451.02$ & $\$ 687.38$ & $-\$ 236.36$ \\
\hline Retreatment & $\$ 13.45$ & $\$ 130.25$ & $-\$ 116.81$ & $\$ 13.48$ & $\$ 100.90$ & $-\$ 87.42$ \\
\hline Total cost of resource use & $\$ 18,833.09$ & $\$ 20,390.14$ & $-\$ 1,557.05$ & $\$ 20,293.91$ & $\$ 24,986.72$ & $-\$ 4,692.81$ \\
\hline Hemostat acquisition cost & $\$ 1,572.93$ & $\$ 69.38$ & $\$ 1,503.55$ & $\$ 1,533.48$ & $\$ 74.02$ & $\$ 1,459.46$ \\
\hline Cost impact $(+) /$ cost savings $(-)$ & $\$ 20,406.02$ & $\$ 20,459.51$ & $-\$ 53.50$ & $\$ 21,827.39$ & $\$ 25,060.73$ & $-\$ 3,233.35$ \\
\hline \multicolumn{7}{|l|}{ Hospital analysis } \\
\hline Resource use from surgical analysis & $\$ 18,833.09$ & $\$ 20,390.13$ & $-\$ 1,557.05$ & $\$ 20,293.91$ & $\$ 24,986.72$ & $-\$ 4,692.81$ \\
\hline Length of stay & $\$ 11,740.62$ & $\$ 13,300.92$ & $-\$ 1,560.31$ & $\$ 10,980.06$ & $\$ 14,290.82$ & $-\$ 3,310.75$ \\
\hline Ventilator use & $\$ 640.59$ & $\$ 1,872.77$ & $-\$ 1,232.18$ & $\$ 689.01$ & $\$ 3,431.46$ & $-\$ 2,742.45$ \\
\hline Total cost of resource use & $\$ 3 I, 214.30$ & $\$ 35,563.84$ & $-\$ 4,349.54$ & $\$ 31,962.98$ & $\$ 42,709.00$ & $-\$ 10,746.01$ \\
\hline Hemostat acquisition cost & $\$ 1,572.93$ & $\$ 69.38$ & $\$ 1,503.55$ & $\$ 1,533.48$ & $\$ 74.02$ & $\$ 1,459.46$ \\
\hline Cost impact $(+) /$ cost savings $(-)$ & $\$ 32,787.23$ & $\$ 35,633.22$ & $-\$ 2,845.99$ & $\$ 33,496.46$ & $\$ 42,783.01$ & $-\$ 9,286.55$ \\
\hline
\end{tabular}

Abbreviation: SoC, standard of care.

(Figure 1C). When additional resources were included for the hospital analysis, results predicted an increased cost savings for hospitals, with the total cost savings for the fibrin sealant patch predicted to reach $\$ 9,287$ per patient (Figure 1D).
The model results were relatively robust to a number of variations in input values and assumptions. Figure 2A (surgical analysis) presents a tornado diagram where the input values were varied using standard deviations or 
A

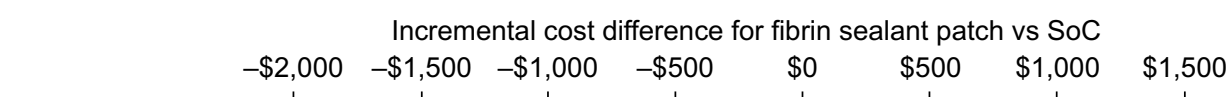

Operating time $( \pm S D)$

Product units used

( \pm SD fibrin sealant patch, $\pm 20 \%$ SoC)

Product cost $( \pm 20 \%)$

OR cost $( \pm 20 \%)$

Transfusion units $( \pm \mathrm{SD})$

Proportion transfused $( \pm 20 \%)$

Transfusion cost $( \pm 20 \%)$

Proportion retreated $( \pm 20 \%)$

Retreat cost $( \pm 20 \%)$

Incremental cost difference for fibrin sealant patch vs SoC

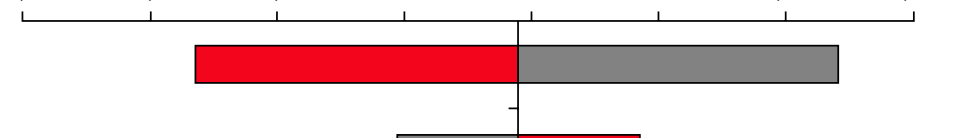


Table 4 Sensitivity analyses using alternative input values for the four-trial composite (overall population)

\begin{tabular}{|c|c|c|}
\hline \multirow[t]{2}{*}{ Analysis scenario with alternative inputs and assumptions } & \multicolumn{2}{|c|}{ Cost impact $(+) /$ savings $(-)$ per patient } \\
\hline & Surgical analysis & Hospital analysis \\
\hline Base case - reference scenario & $-\$ 53.50$ & $-\$ 2,845.99$ \\
\hline $100 \%$ of the fibrin sealant patch arm uses single pad ( $\$ 1,300$ per patient) & $-\$ 326.43$ & $-\$ 3,118.92$ \\
\hline $100 \%$ of the fibrin sealant patch arm uses two pads ( $\$ 2,600$ per patient) & $\$ 973.57$ & $-\$ 1,8 \mid 8.92$ \\
\hline Use total reported OR duration ${ }^{\mathrm{a}}$ & $\$ 425.32$ & $-\$ 2,367.16$ \\
\hline Transfusions that occur at any time during the study ${ }^{b}$ & $-\$ 55.87$ & $-\$ 2,848.36$ \\
\hline Transfusion units: RBC only & $\$ 17.03$ & $-\$ 2,775.46$ \\
\hline Total hospital length of stay & $-\$ 53.5$ & $-\$ 3,457.95$ \\
\hline Inclusion of transfusion complications ${ }^{c}$ & $-\$ 52.91$ & $-\$ 2,845.4$ \\
\hline \multicolumn{3}{|l|}{ Alternative OR $\operatorname{cost}^{44}$} \\
\hline Upper: $\$ 133 /$ minutes & $-\$ 605.19$ & $-\$ 3,397.68$ \\
\hline Lower: $\$ 22 /$ minutes & $\$ 908.35$ & $-\$ 1,884.14$ \\
\hline Alternative transfusion cost: $\$ 522$ per unit ${ }^{35}$ & $-\$ 272.18$ & $-\$ 3,064.67$ \\
\hline
\end{tabular}

Notes: ${ }^{\mathrm{a} T o t a l}$ reported operating time incorporates surgery time and operating room preparation time. ${ }^{\mathrm{b}}$ Transfusions occurring at any time during the study includes both until discharge and postdischarge up to 60 days. 'Transfusion complications rates as reported in the literature..$^{41-43}$

Abbreviations: OR, operating room; RBC, red blood cells.

Table 4 presents additional one-way sensitivity analyses using alternative input values, such as additional literature sources. Results showed that most of the surgical analyses, and all of the hospital analyses, remained cost saving for the fibrin sealant patch compared with SoC. Results appeared most sensitive to lowering operating room cost per minute, as well as increasing the amount of fibrin sealant patch pads used per patient. Results were fairly insensitive to using alternative transfusion endpoints, inclusion of transfusion complications, and changing transfusion costs.

\section{Discussion}

This hospital cost impact analysis predicted that the fibrin sealant patch may be cost saving for hospitals when compared to $\mathrm{SoC}$ in soft tissue and hepatic surgical bleeding patients. Surgical analyses including only a subset of resources collected from the trials (ie, operation time, retreatment, and transfusions) still revealed that the fibrin sealant patch was cost saving compared with SoC; however, the magnitude of the cost savings was less ( $\$ 54$ per patient) compared with hospital analyses $(\$ 2,846$ per patient) that incorporated all resources reported in the trials.

The predicted cost savings with the fibrin sealant patch become most apparent in more problematic bleeds. Specifically, in an exploratory subgroup analysis, the predicted hospital cost savings with the fibrin sealant patch increased to $\$ 9,287$ per patient when focusing on the coagulopathic patients from the four trials, as the differences in resource use became larger between treatment arms. These economic findings align with efficacy data from preclinical and clinical studies. Specifically, a preclinical study reporting on efficacy data in coagulopathic bleeding found that the fibrin sealant patch achieved hemostasis in all cases compared to only $16.7 \%$ with the comparator hemostat. ${ }^{45}$ The quantity of blood lost in this preclinical study was also less with the fibrin sealant patch. Further, in the clinical trials, the differences in hemostatic efficacy at 4 minutes, for the fibrin sealant patch versus SoC, were observed to be larger for more severe bleeding intensities compared with less severe intensities. ${ }^{22,23}$ Further economic analysis in coagulopathic specific populations are needed to verify our findings.

These study results were robust to a number of sensitivity analyses incorporating alternative sources, variation around point estimates, and additional resource items. For the majority of scenarios, the fibrin sealant patch remained cost saving relative to SoC. Results expectedly appeared most sensitive to variations around operation time given the high cost associated with operating room assumed in the base case and the high variability around the point estimate. There is a wide range of costs reported for operating time in the literature and therefore we have assessed the impact of these different options. Surprisingly, results did not vary with the inclusion of literature-reported transfusion complication risk. These results can be explained by the fact that we remained conservative in informing this analysis with very low reported risk of such complications (eg, 0.0071\% of patients transfused experienced a transfusion-related acute lung injury). In the scenarios that predicted a higher cost impact, a very high cost of the fibrin sealant patch or a very low cost of operating room time was assumed.

These results are aligned with recent US health care reform measures, which encourage coordinated care, cost 
awareness, and high-quality care. ${ }^{46,47}$ As cost containment within hospitals becomes increasingly important, health economic analyses can be valuable tools that aid decision makers in the evaluation of the relative clinical benefits and economic impact of adopting new health care technologies. For several regions, including the US, the fibrin sealant patch may not receive separate reimbursement apart from the procedure according to diagnosis-related group structures. In these circumstances, it is critical to illustrate how hospital resources and costs can be averted with new innovative products.

This analysis focused on monetary outcomes partially based on aggregate resource data in the trial and as such is considered a cost analysis rather than a cost-effectiveness evaluation. Quality of life or health utility data are currently not available from the fibrin sealant patch trials and have not been reported for surgical hemostatic products in the literature. Further, mortality was not a primary or secondary endpoint in the fibrin sealant patch trials, rather captured as an adverse event and shown to be reasonably similar between groups. Given these reasons, a cost per quality-adjusted life year gained was not considered as a metric in this evaluation. Disease-specific incremental cost-effectiveness ratios are sometimes used in the context of reporting health economic results but have limitations in that the results can be difficult to interpret in the context of recommended thresholds and relative to other therapeutic categories for decision making. In the context of hemostatic products, cost analyses without incremental cost-effectiveness ratios are the types of evaluations most commonly reported in the literature. ${ }^{48,49}$

Overall, a few studies from the literature have shown that hemostatic products, such as fibrin sealants, may be associated with reduced resource utilization (eg, transfusion and length of hospital stay) compared with SoC. ${ }^{48-53}$ For example, a meta-analysis reported that overall use of fibrin sealants compared with no sealant significantly reduced the rate of blood transfusion by $37 \%$. Positive trends were shown for other clinical outcomes, including hospital length of stay, although the meta-analysis did not show a statistically significant benefit. ${ }^{51}$ The results of the current study are aligned with these published studies demonstrating that several types of hospital resources can be averted with hemostat products. As the fibrin sealant patch displays unique product characteristics and features relative to several currently marketed hemostats, it is expected that the magnitude of the results will vary according to comparator, bleeding intensity, and surgery type. ${ }^{54}$

Interestingly, ventilator time was observed to be nonsignificantly lower with the fibrin sealant patch compared with SoC across trials. Using these data, such resource use was incorporated into our hospital-specific cost analysis that predicted additional cost savings with the fibrin sealant patch. Pulmonary resections did comprise approximately a quarter of surgeries for both trials; however, they appeared well-balanced between treatment groups. A factor that may help to explain this observation with the fibrin sealant patch pertains to transfusions. Evidence suggests that blood transfusion is associated with increased ventilator use, such as with the occurrence of lung-related transfusion complications. ${ }^{55,56}$ In further support, several studies have also reported that blood conservation initiatives and techniques have been shown to significantly reduce ventilator use. ${ }^{57,58}$ Taken together, these studies suggest an intricate relationship between the various types of resources averted with blood conservation methods, including hemostats, such as the fibrin sealant patch.

There are some limitations with this study. First, the clinical trials were not powered for resource outcomes as they were not primary endpoints. ${ }^{22-25}$ This may explain the lack of statistically significant reductions in resource outcomes with the fibrin sealant patch. Nevertheless, nonsignificant reductions in resource use were consistently observed with the fibrin sealant patch versus SoC across the range of outcomes, which was expected given the highly statistically significant benefits observed in hemostatic efficacy. These data suggest that an adequately powered study with resource outcomes as primary endpoints may achieve positive results. Health economic guidelines do recognize the issue that trials are often underpowered for detecting economic outcome differences. ${ }^{59} \mathrm{~A}$ second limitation was that the SoC arm analyzed in two of the trials was primarily composed of Surgicel ${ }^{\circledR}$ Original, which may not always reflect $\mathrm{SoC}$ in the real world. In reality, surgeons may be using other products that may be priced higher than Surgicel ${ }^{\circledR}$ Original with currently unknown efficacy relative to the fibrin sealant patch. Use of these other products was partially reflected in retreatment product use within the trials; however, ongoing clinical trials are being conducted to assess head-to-head performance of the fibrin sealant patch versus other costly agents (eg, Tacho$\left.\mathrm{Sil}^{\circledR}\right) .{ }^{60}$ Third, adverse events were not explicitly included in the analysis as it was assumed that resource use outcomes reported in the trial primarily captured adverse event-related hospital consequences. There were also no trends observed in the adverse event data to suggest they would contribute substantially to the overall results of the analysis. Fourth, the clinical trials were multinational, reflecting resource use in the context of several different health care systems (ie, US, Europe, Australia, and New Zealand). Caution may therefore be needed in interpreting baseline resource use. Finally, the 
analysis focused on the use of the fibrin sealant patch and comparators in the context of the target bleeding site and did not include implications of bleeding at sites other than the target site. Future, real-world studies may be helpful in addressing this issue.

In conclusion, this modeled analysis predicted that the fibrin sealant patch may result in important hospital cost savings in problematic soft tissue and hepatic bleeding. Further studies comparing the fibrin sealant patch use to that of other comparator hemostats and within larger study populations, particularly coagulopathic bleeding, are required to confirm these findings.

\section{Acknowledgment}

The authors would like to thank Bryanna Tibensky who assisted with medical writing services.

\section{Disclosure}

MC, GG, NJ, JB, and RK were employees of Ethicon BioSurgery at the time of manuscript development, manufacturer of the Evarrest ${ }^{\circledR}$ fibrin sealant patch. Cornerstone Research Group (NF, $\mathrm{AH}$, and $\mathrm{SH}$ ) received funding from Ethicon BioSurgery to conduct the study and prepare the manuscript. The authors report no other conflicts of interest in this work.

\section{References}

1. Boucher BA, Traub O. Achieving hemostasis in the surgical field. Pharmacotherapy. 2009;29(7 Pt 2):2S-7S.

2. Marietta M, Facchini L, Pedrazzi P, Busani S, Torelli G. Pathophysiology of bleeding in surgery. Transplant Proc. 2006;38(3):812-814.

3. Reynolds MW, Clark J, Crean S, Samudrala S. Risk of bleeding in surgical patients treated with topical bovine thrombin sealants: a review of the literature. Patient Saf Surg. 2008;2:5.

4. Saif R, Jacob M, Robinson S, et al. Use of fibrin-based sealants and gelatin-matrix hemostats in laparoscopic liver surgery. Surg Laparosc Endosc Percutan Tech. 2011;21(3):131-141.

5. Shander A, Hofmann A, Gombotz H, Theusinger OM, Spahn DR. Estimating the cost of blood: past, present, and future directions. Best Pract Res Clin Anaesthesiol. 2007;21(2):271-289.

6. Samudrala S. Topical hemostatic agents in surgery: a surgeon's perspective. AORN J. 2008;88(3):S2-S11.

7. Jairath V, Kahan BC, Stanworth SJ, et al. Prevalence, management, and outcomes of patients with coagulopathy after acute nonvariceal upper gastrointestinal bleeding in the United Kingdom. Transfusion. 2013;53(5):1069-1076.

8. Christensen MC, Krapf S, Kempel A, von Heymann C. Costs of excessive postoperative hemorrhage in cardiac surgery. JThoracic Cardiovasc Surg. 2009;138(3):687-693.

9. Claridge JA, Sawyer RG, Schulman AM, McLemore EC, Young JS. Blood transfusions correlate with infections in trauma patients in a dose-dependent manner. Am Surg. 2002;68(7):566-572.

10. Lauzier F, Arnold DM, Rabbat C, et al. Risk factors and impact of major bleeding in critically ill patients receiving heparin thromboprophylaxis. Intensive Care Med. 2013;39(12):2135-2143.

11. Marietta M, Pedrazzi P, Girardis M, Luppi M. Massive bleeding: are we doing our best? Transfus Apher Sci. 2011;45(3):287-290.

12. Stokes ME, Ye X, Shah M, Mercaldi K, Reynolds MW, Rupnow MF, Hammond J. Impact of bleeding-related complications and/or blood product transfusions on hospital costs in inpatient surgical patients. BMC Health Serv Res. 2011;11:135.
13. Bochicchio GV, Napolitano L, Joshi M, Bochicchio K, Meyer W, Scalea TM. Outcome analysis of blood product transfusion in trauma patients: a prospective, risk-adjusted study. World J Surg. 2008;32(10):2185-2189.

14. Doussau A, Perez P, Puntous M, et al. Fresh-frozen plasma transfusion did not reduce 30-day mortality in patients undergoing cardiopulmonary bypass cardiac surgery with excessive bleeding: the PLASMACARD multicenter cohort study. Transfusion. 2014;54(4):1114-1124.

15. Kooby DA, Stockman J, Ben-Porat L, et al. Influence of transfusions on perioperative and long-term outcome in patients following hepatic resection for colorectal metastases. Ann Surg. 2003;237(6):860-869; discussion 869-870.

16. Schreiber MA, Neveleff DJ. Achieving hemostasis with topical hemostats: making clinically and economically appropriate decisions in the surgical and trauma settings. AORN J. 2011;94(5):S1-S20.

17. Corral M, Ferko N, Hollman S, Broder M, Chang E. Health and economic outcomes associated with uncontrolled surgical bleeding: a retrospective analysis of the Premier Perspectives Database. Clinicoecon Outcomes Res. 2015;7:409-421.

18. Spotnitz WD. Efficacy and safety of fibrin sealant for tissue adherence in facial rhytidectomy. Clin Cosmet Investig Dermatol. 2012;5:43-51.

19. Spotnitz WD, Burks S. Hemostats, sealants, and adhesives: components of the surgical toolbox. Transfusion. 2008;48(7):1502-1516.

20. Rossaint R, Bouillon B, Cerny V, et al. Management of bleeding following major trauma: an updated European guideline. Crit Care. 2010;14(2):R52.

21. Spotnitz WD, Burks S. Hemostats, sealants, and adhesives III: a new update as well as cost and regulatory considerations for components of the surgical toolbox. Transfusion. 2012;52(10):2243-2255.

22. Fischer CP, Bochicchio G, Shen J, Patel B, Batiller J, Hart JC. A prospective, randomized, controlled trial of the efficacy and safety of fibrin pad as an adjunct to control soft tissue bleeding during abdominal, retroperitoneal, pelvic, and thoracic surgery. J Am Coll Surg. 2013;217(3): 385-393.

23. Koea J, Baldwin P, Shen J, et al. Safety and hemostatic effectiveness of the fibrin pad for severe soft-tissue bleeding during abdominal, retroperitoneal, pelvic, and thoracic (non-cardiac) surgery: a randomized, controlled, superiority trial. World J Surg. 2015;39(11):2663-2669.

24. Koea JB, Batiller J, Patel B, et al. A phase III, randomized, controlled, superiority trial evaluating the fibrin pad versus standard of care in controlling parenchymal bleeding during elective hepatic surgery. $H P B$ (Oxford). 2013;15(1):61-70.

25. Koea J, Batiller J, Aguirre N, Shen J, Kocharian R, Bochicchio G, Garden OJ. A multicentre, prospective, randomized, controlled trial comparing EVARREST fibrin sealant patch to standard of care in controlling bleeding following elective hepatectomy: anatomic versus non-anatomic resection. HPB (Oxford). 2016;18(3):221-228.

26. United States Department of Labor. Bureau of Labor Statistics: Consumer Price Index-All Urban Consumers. Available from: http://data. bls.gov/cgi-bin/surveymost?cu. Accessed March 18, 2016.

27. Ethicon U.S. LLC. a Johnson \& Johnson Company. List prices for topical absorbable hemostats; 2016. Available from: http://www.ethicon. com/healthcare-professionals/products/biosurgery. Accessed July 8, 2016.

28. Dan Scott \& Associates. BloodSTOP hemostatic gauze. Available from: http://www.danscottandassociates.com/uploads/4/2/7/4/42749367/11_ bloodstop.pdf. Accessed June 18, 2015.

29. Shippert R. A study of time-dependent operating room fees and how to save $\$ 100000$ by using time-saving products. Am J Cosmetic Surg. 2005;22(1):25-34.

30. McMenamin P. 2009 Registered nurses employment and earning. American Nurses Association. Available from: http://www.nursingworld.org/MainMenuCategories/Policy-Advocacy/Positions-andResolutions/Issue-Briefs/RN-Employment-Earnings.pdf. Accessed August 20, 2014.

31. Farnworth LR, Lemay DE, Wooldridge T, et al. A comparison of operative times in arthroscopic ACL reconstruction between orthopaedic faculty and residents: the financial impact of orthopaedic surgical training in the operating room. Iowa Orthop J. 2001;21:31-35. 
32. The Henry J. Kaiser Family Foundation. Hospital Adjusted Expenses per Inpatient Day. Available from: http://kff.org/other/state-indicator/ expenses-per-inpatient-day/. Accessed March 25, 2015.

33. Halpern NA, Pastores SM. Critical care medicine in the United States 2000-2005: an analysis of bed numbers, occupancy rates, payer mix, and costs. Crit Care Med. 2010;38(1):65-71.

34. Etchason J, Petz L, Keeler E, et al. The cost effectiveness of preoperative autologous blood donations. $N$ Engl J Med. 1995;332(11):719-724.

35. Shander A, Goodnough LT. Why an alternative to blood transfusion? Crit Care Clin. 2009;25(2):261-277, Table of contents.

36. Toner RW, Pizzi L, Leas B, Ballas SK, Quigley A, Goldfarb NI. Costs to hospitals of acquiring and processing blood in the US: a survey of hospital-based blood banks and transfusion services. Appl Health Econ Health Policy. 2011;9(1):29-37.

37. Dasta JF, McLaughlin TP, Mody SH, Piech CT. Daily cost of an intensive care unit day: the contribution of mechanical ventilation. Crit Care Med. 2005;33(6):1266-1271.

38. U.S. National Library of Medicine: MedlinePlus. Prothrombin Time (PT); 2013. Available from: http://www.nlm.nih.gov/medlineplus/ency/ article/003652.htm. Accessed June 11, 2015.

39. U.S. National Library of Medicine: MedlinePlus. Partial Thromboplastin Time (PTT); 2013. Available from: http://www.nlm.nih.gov/ medlineplus/ency/article/003653.htm. Accessed June 11, 2015.

40. U.S. National Library of Medicine: MedlinePlus. Fibrinogen; 2013. Available from: http://www.nlm.nih.gov/medlineplus/ency/ article/003650.htm. Accessed June 11, 2015.

41. Linden JV, Wagner K, Voytovich AE, Sheehan J. Transfusion errors in New York State: an analysis of 10 years' experience. Transfusion. 2000;40(10):1207-1213.

42. Stainsby D, Jones H, Asher D, et al. Serious hazards of transfusion: a decade of hemovigilance in the UK. Transfus Med Rev. 2006;20(4):273-282.

43. Steuten L, Vallejo-Torres L, Bastide P, Buxton M. Analysing uncertainty around costs of innovative medical technologies: the case of fibrin sealant (QUIXIL) for total knee replacement. Health Policy. 2009;89(1):46-57.

44. Macario A. What does one minute of operating room time cost? J Clin Anesth. 2010;22(4):233-236.

45. Hutchinson R, Shnode P, Wilson S, Daly I. A comparison of hemostatic effectiveness and safety of two fibrin sealant patch products after severe renal hemorrhage in swine model of dilutional and hypothermic coagulopathy. J Trauma Treat. 2015;4(2).

46. Centres for Medicare \& Medcaid Services. Hospital Value Based Purchasing. Available from: https://www.cms.gov/Medicare/QualityInitiatives-Patient-Assessment-Instruments/hospital-value-basedpurchasing/index.html?redirect=/Hospital-Value-Based-Purchasing/. Accessed July 14, 2015.

47. U.S Department of health and human services. Annual Progress Report to Congress: National Strategy for Quality Improvement in Health Care. September 30, 2013; 2013

48. Anegg U, Rychlik R, Smolle-Juttner F. Do the benefits of shorter hospital stay associated with the use of fleece-bound sealing outweigh the cost of the materials? Interact Cardiovasc Thorac Surg. 2008;7(2):292-296; discussion 226.
49. Kallinowski F, Pfeil T, Ulbrich W. Quality management in surgical intervention-a prospective outcomes research study of fleece-bound tissue gluing (TachoSil®). Gesundh ökon Qual manag. 2005;10: 151-159.

50. Bernasek TL, Burris RB, Fujii H, Levering MF, Polikandriotis JA, Patterson JJ. Effect on blood loss and cost-effectiveness of pain cocktails, platelet-rich plasma, or fibrin sealant after total knee arthroplasty. J Arthroplasty. 2012;27(8):1448-1451.

51. Carless PA, Henry DA, Anthony DM. Fibrin sealant use for minimising peri-operative allogeneic blood transfusion. Cochrane Database Syst Rev. 2003(2):CD004171.

52. Maharaj M, Diamond C, Williams D, Seikaly H, Harris J. Tisseel to reduce postparotidectomy wound drainage: randomized, prospective, controlled trial. J Otolaryngol. 2006;35(1):36-39.

53. Massin P, Scemama C, Jeanrot C, Boyer P. Does fibrin sealant use in total knee replacement reduce transfusion rates? A non-randomised comparative study. Orthop Traumatol Surg Res. 2012;98(2): 180-185.

54. Ethicon U.S. LLC. EVARREST Fibrin Selant Patch [prescribing information]. 2015.

55. Goodman AM, Pollack MM, Patel KM, Luban NL. Pediatric red blood cell transfusions increase resource use. J Pediatr. 2003;142(2): 123-127.

56. Vlaar AP, Juffermans NP. Transfusion-related acute lung injury: a clinical review. Lancet. 2013;382(9896):984-994.

57. Karimi M, Florentino-Pineda I, Weatherred T, Qadeer A, Rosenberg CA, Hudacko A, Ryu D. Blood conservation operations in pediatric cardiac patients: a paradigm shift of blood use. Ann Thorac Surg. 2013;95(3):962-967.

58. Lapar DJ, Crosby IK, Ailawadi G, et al. Blood product conservation is associated with improved outcomes and reduced costs after cardiac surgery. J Thorac Cardiovasc Surg. 2013;145(3):796-804.

59. Ramsey SD, Willke RJ, Glick H, et al. Cost-effectiveness analysis alongside clinical trials II-An ISPOR Good Research Practices Task Force report. Value Health. 2015;18(2):161-172.

60. The fibrin pad cardiovascular study (Phase III). Available from: https:/clinicaltrials.gov/ct2/show/NCT02040428?term=fibrin+pad\&r ank=3. Accessed June 18, 2015.

61. Truven Health Analytics Micromedex Solutions. Red Book Online: TachoSil. Available from: http://www.micromedexsolutions.com/ micromedex2/librarian. Accessed July 7, 2016.

62. DavidG,LimS, GunnarssonC,KocharianR, RoyS. Similarpatientoutcomes yet different hospital costs between flowable hemostatic agents. J Med Econ. 2015;18(9):735-745

63. Micro Clips and Clamps, Roboz Surgical Store. Available from: http:// shopping.roboz.com/Micro-Clips-Clamps. Accessed June 18, 2015.

64. KERLIX ${ }^{\mathrm{TM}}$ Laparotomy Sponges Sterile Tray Pack, Case. Available from: http://www.dhphomedelivery.com/productcart/pc/viewPrd.asp? idcategory=130\&idproduct=951. Accessed June 18, 2015.

65. Hubner M, Demartines N, Muller S, Dindo D, Clavien PA, Hahnloser D. Prospective randomized study of monopolar scissors, bipolar vessel sealer and ultrasonic shears in laparoscopic colorectal surgery. Br J Surg. 2008;95(9):1098-1104. 


\section{Supplementary materials}

Table SI Initial product utilization** and cost according to analysis population for SoC arm of all four trials

\begin{tabular}{|c|c|c|c|c|c|c|c|c|c|}
\hline \multirow[t]{3}{*}{ Initial product } & \multirow[t]{3}{*}{ Unit cost } & \multicolumn{8}{|c|}{ Total units } \\
\hline & & \multicolumn{2}{|c|}{$\begin{array}{l}\text { Mild-moderate soft } \\
\text { tissue' }\end{array}$} & \multicolumn{2}{|c|}{ Severe soft tissue $^{2}$} & \multicolumn{2}{|c|}{ Hepatic tissue $^{3}$} & \multicolumn{2}{|c|}{ Hepatic tissue $^{4}$} \\
\hline & & Overall & Coagulopathic & Overall & Coagulopathic & Overall & Coagulopathic & Overall & Coagulopathic \\
\hline ORC (Surgicel ${ }^{\circledR}$ & $\$ 68.92^{5}$ & 30 & 10 & 28 & 7 & 15 & 2 & 34 & 7 \\
\hline \multicolumn{10}{|l|}{ Original) } \\
\hline $\begin{array}{l}\text { Advanced ORC } \\
\text { (ie, Surgicel }{ }^{\circledR} \text { Fibrillar) }\end{array}$ & $\$ 156.18^{5}$ & - & - & - & - & - & - & I & 1 \\
\hline $\begin{array}{l}\text { Fibrin sealant } \\
\text { (ie, Evicel) }\end{array}$ & $\$ 399.10^{5}$ & - & - & I & 1 & - & - & - & - \\
\hline TachoComb/Tachosil $^{\circledR}$ & $\$ 400.43^{6}$ & - & - & I & - & I & - & - & - \\
\hline Surgiflo ${ }^{\circledR}$ & $\$ 246.66^{5}$ & - & - & - & - & 2 & I & I & 1 \\
\hline Manual compression & $\$ 7^{7}$ & - & - & 31 & 9 & 43 & II & 49 & 12 \\
\hline Sutures & $\$ 33^{8}$ & - & - & 1 & I & 1 & - & - & - \\
\hline Ligation & $\$ 0$ & - & & I & I & - & - & - & - \\
\hline Argon beam & $\$ 0$ & - & - & - & - & I & - & I & I \\
\hline Cautery & $\$ 0$ & - & - & 1 & - & - & - & - & - \\
\hline Diathermy & $\$ 0$ & - & - & - & - & - & - & I & - \\
\hline $\begin{array}{l}\text { Weighted average } \\
\text { retreatment cost }\end{array}$ & & $\$ 68.92$ & $\$ 68.92$ & $\$ 93.11$ & $\$ 108.62$ & $\$ 51.40$ & $\$ 41.96$ & $\$ 63.04$ & $\$ 80.77$ \\
\hline
\end{tabular}

Notes: All costs are reported in US dollars and inflated to 2015 dollars using the Consumer Price Index. ${ }^{9}$ Product sizes were not recorded in the clinical trial; as such, the cost of ORC, advanced ORC, and fibrin sealant were based on the average of all sizes available and Surgiflo ${ }^{\circledR}$ cost includes thrombin. ${ }^{* *}$ Clinical study reports available to the public via correspondence with authors.

Abbreviations: ORC, oxidized regenerated cellulose; SoC, standard of care.

Table S2 Retreatment utilization** and cost according to analysis population for all four trials.

\begin{tabular}{|c|c|c|c|c|c|c|c|c|c|}
\hline \multirow{3}{*}{$\begin{array}{l}\text { Retreatment } \\
\text { product }\end{array}$} & \multirow[t]{3}{*}{ Unit cost } & \multicolumn{8}{|c|}{ Total units } \\
\hline & & \multicolumn{2}{|c|}{$\begin{array}{l}\text { Mild-moderate soft } \\
\text { tissue' }^{\prime}\end{array}$} & \multicolumn{2}{|c|}{ Severe soft tissue $^{2}$} & \multicolumn{2}{|c|}{ Hepatic tissue $^{3}$} & \multicolumn{2}{|c|}{ Hepatic tissue $^{4}$} \\
\hline & & Overall & $\overline{\text { Coagulopathic }}$ & Overall & Coagulopathic & Overall & $\overline{\text { Coagulopathic }}$ & Overall & Coagulopathic \\
\hline ORC (Surgicel ${ }^{\circledR}$ & $\$ 68.92^{5}$ & 8 & 2 & 4 & I & 7 & 2 & 14 & 2 \\
\hline \multicolumn{10}{|l|}{ Original) } \\
\hline $\begin{array}{l}\text { Advanced ORC } \\
\text { (ie, Surgicel }{ }^{\circledR} \text { Fibrillar) }\end{array}$ & $\$ 156.18^{5}$ & I & I & - & - & - & - & - & - \\
\hline $\begin{array}{l}\text { Fibrin sealant } \\
\text { (ie, Evicel) }\end{array}$ & $\$ 399.10^{5}$ & I & I & - & - & - & - & - & - \\
\hline TachoComb/Tachosil ${ }^{\circledR}$ & $\$ 400.43^{6}$ & - & - & - & - & 5 & - & 5 & I \\
\hline Surgiflo ${ }^{\circledR}$ & $\$ 246.66^{5}$ & - & - & - & - & I & - & I & - \\
\hline FloSeal & $\$ 349.80^{10}$ & - & - & - & - & I & - & - & - \\
\hline $\begin{array}{l}\text { Fibrin sealant patch } \\
\text { small }(5.1 \times 10.2 \mathrm{~cm})\end{array}$ & $\$ 1,300^{5}$ & - & - & I & I & I & - & 2 & I \\
\hline $\begin{array}{l}\text { Fibrin sealant patch } \\
\text { large }(2-5.1 \times 10.2 \mathrm{~cm})\end{array}$ & $\$ 2,600^{5}$ & - & - & 2 & - & 2 & - & - & - \\
\hline Manual compression & $\$ 7^{7}$ & I & - & 4 & 2 & II & 7 & 8 & I \\
\hline Sutures & $\$ 33^{8}$ & 5 & 5 & 4 & I & 10 & 4 & 12 & 2 \\
\hline Microclip & $\$ 70^{11}$ & I & I & - & - & - & - & - & - \\
\hline Laparotomy pad & $\$ 2^{12}$ & I & I & - & - & - & - & - & - \\
\hline Argon beam & $\$ 0$ & I & 1 & - & - & 16 & 6 & - & 2 \\
\hline Ligasure & $\$ 0$ & - & - & I & I & - & - & - & - \\
\hline Cautery & $\$ 0$ & - & - & 6 & I & 2 & - & I & I \\
\hline Felt pieces & $\$ 0$ & - & - & I & - & - & - & - & - \\
\hline Gauze & $\$ 7$ & - & - & I & - & - & - & - & - \\
\hline Clips & $\$ 8^{13}$ & - & - & I & I & I & - & - & - \\
\hline
\end{tabular}


Table S2 (Continued)

\begin{tabular}{|c|c|c|c|c|c|c|c|c|c|}
\hline \multirow{3}{*}{$\begin{array}{l}\text { Retreatment } \\
\text { product }\end{array}$} & \multirow[t]{3}{*}{ Unit cost } & \multicolumn{8}{|c|}{ Total units } \\
\hline & & \multicolumn{2}{|c|}{$\begin{array}{l}\text { Mild-moderate soft } \\
\text { tissue' }^{\prime}\end{array}$} & \multicolumn{2}{|c|}{ Severe soft tissue $^{2}$} & \multicolumn{2}{|c|}{ Hepatic tissue $^{3}$} & \multicolumn{2}{|c|}{ Hepatic tissue $^{4}$} \\
\hline & & Overall & Coagulopathic & Overall & $\overline{\text { Coagulopathic }}$ & Overall & Coagulopathic & Overall & Coagulopathic \\
\hline Diathermy & $\$ 0$ & - & - & - & - & 2 & - & I & I \\
\hline Fibrinalin & $\$ 0$ & - & - & - & - & I & I & - & - \\
\hline Aquamantys & $\$ 0$ & - & - & - & - & - & - & 1 & - \\
\hline Weighted average & & $\$ 90.06$ & $\$ 155.07$ & $\$ 347.90$ & $\$ 284.70$ & $\$ 302.91$ & $\$ 31.91$ & $\$ 202.14$ & $\$ 238.92$ \\
\hline Retreatment cost & & & & & & & & & \\
\hline
\end{tabular}

Notes: All costs are reported in US dollars and inflated to 2015 dollars using the Consumer Price Index. ${ }^{9}$ Product sizes were not recorded in the clinical trial; as such, the cost of ORC, advanced ORC, and fibrin sealant were based on the average of all sizes available and Surgiflo ${ }^{\circledR}$ cost includes thrombin. ${ }^{* *} \mathrm{Clinical}$ study reports available to the public via correspondence with authors.

Abbreviations: ORC, oxidized regenerated cellulose; SoC, standard of care.

\section{References}

1. Fischer CP, Bochicchio G, Shen J, Patel B, Batiller J, Hart JC. A prospective, randomized, controlled trial of the efficacy and safety of fibrin pad as an adjunct to control soft tissue bleeding during abdominal, retroperitoneal, pelvic, and thoracic surgery. J Am Coll Surg. 2013;217(3): 385-393.

2. Koea J, Baldwin P, Shen J, et al. Safety and hemostatic effectiveness of the fibrin pad for severe soft-tissue bleeding during abdominal, retroperitoneal, pelvic, and thoracic (non-cardiac) surgery: a randomized, controlled, superiority trial. World J Surg. 2015;39(11): 2663-2669.

3. Koea JB, Batiller J, Patel B, et al. A phase III, randomized, controlled, superiority trial evaluating the fibrin pad versus standard of care in controlling parenchymal bleeding during elective hepatic surgery. $H P B$ (Oxford). 2013;15(1):61-70.

4. Koea J, Batiller J, Aguirre N, Shen J, Kocharian R, Bochicchio G, Garden OJ. A multicentre, prospective, randomized, controlled trial comparing EVARREST fibrin sealant patch to standard of care in controlling bleeding following elective hepatectomy: anatomic versus non-anatomic resection. HPB (Oxford). 2016;18(3):221-228.

5. Ethicon U.S. LLC. a Johnson \& Johnson Company. List prices for topical absorbable hemostats; 2016. Available from: http://www.ethicon. com/healthcare-professionals/products/biosurgery. Accessed July 8, 2016.
6. Truven Health Analytics Micromedex Solutions. Red Book Online: TachoSil. Available from: http://www.micromedexsolutions.com/ micromedex2/librarian. Accessed July 7, 2016.

7. Dan Scott \& Associates. BloodSTOP hemostatic gauze. Available from: http://www.danscottandassociates.com/uploads/4/2/7/4/42749367/11_ bloodstop.pdf. Accessed June 18, 2015.

8. Anegg U, Rychlik R, Smolle-Juttner F. Do the benefits of shorter hospital stay associated with the use of fleece-bound sealing outweigh the cost of the materials? Interact Cardiovasc Thorac Surg. 2008;7(2):292-296; discussion 226.

9. United States Department of Labor. Bureau of Labor Statistics: Consumer Price Index-All Urban Consumers. Available from: http://data. bls.gov/cgi-bin/surveymost?cu. Accessed March 18, 2016.

10. David G, Lim S, Gunnarsson C, Kocharian R, Roy S. Similar patient outcomes yet different hospital costs between flowable hemostatic agents. J Med Econ. 2015;18(9):735-745.

11. Micro Clips and Clamps, Roboz Surgical Store. Available from: http:// shopping.roboz.com/Micro-Clips-Clamps. Accessed June 18, 2015.

12. KERLIX ${ }^{\mathrm{TM}}$ Laparotomy Sponges Sterile Tray Pack, Case. Available from: http://www.dhphomedelivery.com/productcart/pc/viewPrd.asp? idcategory=130\&idproduct=951. Accessed June 18, 2015.

13. HubnerM, Demartines N, Muller S, Dindo D, Clavien PA, Hahnloser D. Prospective randomized study of monopolar scissors, bipolar vessel sealer and ultrasonic shears in laparoscopic colorectal surgery. BrJ Surg. 2008;95(9): $1098-1104$.

\section{ClinicoEconomics and Outcomes Research}

\section{Publish your work in this journal}

ClinicoEconomics and Outcomes Research is an international, peerreviewed open-access journal focusing on health technology assessment, pharmacoeconomics and outcomes research in the areas of diagnosis, medical devices, and clinical, surgical and pharmacological intervention. The economic impact of health policy and health systems organization also constitute important areas of coverage. The manuscript management system is completely online and includes a very quick and fair peer-review system, which is all easy to use. Visit http://www.dovepress.com/testimonials.php to read real quotes from published authors. 